\title{
FOTOGRAFIAS DE ÁFRICA: ENTRE INVENÇÕES E AVENTURAS
}

\author{
Raphaela Desiderio*, Ivaine Maria Tonini **
}

\begin{abstract}
*Doutoranda no Programa de Pós-Graduação em Geografia da Universidade Federal do Rio Grande do Sul - UFRGS, linha de pesquisa Ensino de Geografia. Bolsista da CAPES - Coordenação de Aperfeiçoamento de Pessoal. Membro do Grupo Geografias de Experiências da Universidade do Estado de Santa Catarina, um dos polos que integram a Rede de Pesquisa Nacional: Imagens, Geografias e Educação: intenções, dispersões e articulações. ** Professora doutora no Programa de Pós-Graduação em Geografia da Universidade Federal do Rio Grande do Sul - UFRGS, linha de pesquisa Ensino de Geografia. Orientadora da pesquisa em andamento.).
\end{abstract}

Recebido em 06/2016. Aceito para publicação em 07/2016.

Versão online publicada em 06/2018 (http://seer.ufrgs.br/paraonde)

\begin{abstract}
Resumo: 0 artigo intenciona problematizar fotografias didáticas de África presentes na Geografia Escolar. Trata de dois exercícios de mobilização de pensamento em um espaço de formação inicial de professores de Geografia: o primeiro trata de compreender qual ideia de África está presente em um livro didático e suas implicações para a construção de saberes sobre o continente e o segundo intenciona deslocar, através de fotografias do cotidiano dos africanos disponíveis em rede social, o pensamento para a existência de práticas pedagógicas em Geografia que viabilizem discussões e enfrentamento das questões raciais e da educação pelas imagens na Educação Básica. Os exercícios oportunizaram espaços de discussões sobre a ideia de África que permeia a Geografia Escolar, mostraram, ao mesmo tempo, a força das fotografias na validação e reprodução de discursos hegemônicos eurocêntricos e um descompasso com as diretrizes para a Educação das Relações Étnico-raciais, mas também proporcionaram encontros com fotografias que são capazes de deslocar nossos olhares e pensamentos para a abordagem de África no plural.
\end{abstract}

Palavras-chave: África. Fotografia. Geografia Escolar.

\section{PHOTOGRAPHY OF AFRICA: BETWEEN INVENTIONS AND ADVENTURES}

\begin{abstract}
The article intends to problematize didactic photographs of Africa present in the School Geography. It deals with two exercises of thought mobilization in a space of initial formation of teachers of Geography: the first tries to understand which idea of Africa is present in a didactic book and its implications for the construction of knowledge about the continent and the second intention to move, through photographs of the daily life of Africans available in social network, the thought for the existence of pedagogical practices in Geography that enable discussion and confrontation of racial issues and education through images in Basic Education. The exercises provided space for discussions on the idea of Africa that permeates the School Geography. At the same time, they showed the strength of the photographs in the validation and reproduction of Eurocentric hegemonic discourses and a mismatch with the guidelines for the Education of Ethnic-Racial Relations, but also provided encounters with photographs that are capable of shifting our looks and thoughts to the approach of Africa in the plural.
\end{abstract}

Keywords: : Africa. Photography. School Geography.

\section{INTRODUÇÃO}

No ensaio $O$ nome difamado da África, 2012, o escritor nigeriano, Chinua Achebe nos convida a pensar África a partir de uma perspectiva que não esteja pautada pelo viés eurocêntrico e ocidental. Para ele é uma "grande ironia da história e da geografia" que África “[...] ocupe no psiquismo europeu o ponto mais extremo da alteridade; que ela seja, na verdade, a antítese da Europa" (ACHEBE, 2012, p.83).

Achebe nomeia essa posição de alteridade e antítese como "paradoxo da proximidade". Questiona, a partir de elementos geográficos, essa posição que África ocupa no imaginário europeu deixando de lado a história, a Geografia também 
pode nos dar uma aula, à sua maneira, sobre o paradoxo da proximidade. Essa lição, que provavelmente não foi percebida por ninguém, exceto por aqueles de nós que vivíamos na África Ocidental nos últimos dias do Império Britânico, foi a ridícula igualdade longitudinal entre Londres, a poderosa metrópole imperial, e Acra, o acampamento rústico e rebelde da insurreição colonial; de modo que, apesar das situações tão desiguais na vida, as duas cidades eram nomeadas pelo mesmo meridiano de Greenwich e, assim, fadadas a estar sempre juntas na mesma hora do dia!" (ACHEBE, 2012, p. 83).

Apesar de estarem longitudinalmente riscadas, marcadas pela mesma linha imaginária que divide o mundo em Ocidente e Oriente: Londres e Acra (capital de Gana) têm "[...] experiências muito diferentes com a temperatura do meio-dia, por exemplo, que talvez tenha dado a seus habitantes, ao longo de muitas eras, uma cor de pele radicalmente diferente. Assim, as diferenças existem, se é isso que se está procurando" (Ibid., p. 83). Para o escritor essas diferenças podem explicar de forma bastante satisfatória a imagem que África tem representado para a Europa: a do "diferente", do "estrangeiro", do "exótico", imagem que não tem origem na ignorância a respeito desse território e sua gente, mas que é fruto de uma "[...] invenção deliberada, concebida para facilitar dois gigantescos eventos históricos: o tráfico transatlântico de escravos e a colonização da África pela Europa [...]" (ACHEBE, 2012, p. 83).

A intenção deste artigo é pensar África e sua abordagem na Geografia Escolar a partir da análise de fotografias presentes em um livro didático. 0 desejo de nos debruçarmos sobre essas fotografias vem primeiramente de um encontro com professores em formação inicial ${ }^{1}$ diante do desafio de planejar e ministrar aulas de Geografia de África para turmas do Ensino Fundamental junto à disciplina de Estágio Curricular Supervisionado.

0 primeiro exercício: mirar as fotografias presentes nesse aparato pedagógico, o livro didático, para compreender qual ideia de África estava presente nesse material e era acessada pelos estudantes na escola campo de estágio ${ }^{2}$ e o que os professores em formação poderiam pensar com e a partir delas no planejamento e nas aulas de Geografia. Qual ideia de África na Geografia Escolar? Em que medida as fotografias contribui para a construção dessa ideia sobre o continente?

A partir dessa leitura e discussões a respeito da ideia de África presente no livro didático experimentamos, através de fotografias disponíveis em um perfil de uma rede social, deslocarmos nossos olhares para outras Áfricas. Áfricas porque as

\footnotetext{
1 Curso de Licenciatura em Geografia na Universidade do Estado de
Santa Catarina - UDESC. A autora Raphaela Desiderio atuou como

1 Curso de Licenciatura em Geografia na Universidade do Estado de
Santa Catarina - UDESC. A autora Raphaela Desiderio atuou como professora colaboradora no curso de graduação em Geografia entre os anos de 2013 e 2016.

2 E.E.B Simão José Hess. Escola campo de Estágio Curricular Supervisionado: Prática de Ensino em Geografia II - Ensino Fundamental.
} fotografias disponíveis na rede possibilitaram um exercício de mobilização do pensamento na direção de diferentes encontros com o continente. 0 encontro com fotografias que não estão a serviço da Geografia Colonial, da invenção e da ideia de África como um espaço homogêneo e construído a partir dos clichês, do olhar e do discurso eurocentrado.

\section{OFICINAS DE INVENÇÃO: FOTOGRAFIAS DIDÁTICAS DE ÁFRICA NA GEOGRAFIA ESCOLAR}

Na contemporaneidade sabe-se da presença massiva e constante das imagens no cotidiano das pessoas, do seu poder de atração e influência sobre os indivíduos, além de sua capacidade de ser fácil e rapidamente absorvida (VALLADARES, 2015). Na Geografia Escolar, as imagens aparecem como estratégia para exploração da leitura geográfica do mundo, ou seja, potentes como criadoras de informação e conhecimento. Nesse trabalho de pesquisa se tornam ferramenta capaz de criar aberturas para pensarmos os processos de produção e organização do espaço geográfico através da fotografia.

As fotografias são fontes de informação, pois dizem o que existem. São "uma interpretação do mundo", "experiências capturadas" e, "[...] fornecem um testemunho". Algo de que ouvimos falar, mas de que duvidamos parece comprovado quando nos mostram um foto" (SONTAG, 2004, p.32). Nesse sentido, a fotografia adquire um status de "verdade", pois através dela é possível comprovar o dito.

Também são capazes de produzir conhecimento uma vez que se convertem experiências individuais em imagens. A captura de uma imagem através de uma câmera ou de um telefone celular e seu compartilhamento faz circular experiências individuais nos e com os lugares.

Ao sermos atravessados pelas fotografias presentes no cotidiano, inventamos modos de aprender e conhecer sobre os lugares do mundo que não podemos ver ou experimentar com nossos próprios olhos. Nesse sentido, as fotografias são capazes de criar verdades e realidades acerca dos lugares, participam da construção de nossa imaginação do mundo contemporâneo e, por isso, interferem na forma como concebemos o espaço geográfico. Mas é importante ressaltar que em um tempo e, "[...] em situações em que a maioria das pessoas usa as fotos, seu valor como informação é da mesma ordem que da ficção" (SONTAG, 2004, p. 32).

Para Gianni Vattimo (apud Larrosa, 2004, p. 153), nossa sociedade pode ser caracterizada como uma "sociedade da comunicação generalizada". Uma sociedade em que os aparatos de comunicação de massa são "[...] determinantes para a produção, reprodução e dissolução disso que chamamos realidade" (LARROSA, 2004, p. 153).

Dentre os "aparatos de comunicação em massa" estão os periódicos, o rádio, a televisão, o cinema. Há também os aparatos culturais 
educacionais de massa, categoria na qual incluímos os livros didáticos, já que no âmbito das escolas públicas, são responsáveis e determinantes para a produção, reprodução e dissolução da "realidade" sobre os saberes.

Em uma sociedade que vive a "época da globalização informativa e comunicativa" (LARROSA, 2004, p. 153), a "realidade" parece estar sendo produzida e dissolvida constantemente e nela cabem diferentes interpretações sobre o mundo. Nessa perspectiva, para Larrosa (2004, p.153) “[...] é a mesma coisa dizer "é verdade", e "é certo" ou "é seguro" ou é objetivo" ou, até mesmo, "é real".

Para Tonini (2011, p. 153) as imagens presentes nos livros didáticos são produtoras de significados e, esses "[...] podem ser questionados, pois foram construídos no interior de uma determinada cultura, a partir de jogos de linguagem e de sistemas de classificação que os colocam em permanente deslocamento".

Discutir essa produção de significados é bastante significativo já "as fotografias atualmente constituem cerca da metade do material impresso nos livros didáticos de Geografia, sendo em maior número do que qualquer outra imagem, inclusive mapas" (OLIVEIRA JR.; SOARES, 2012, p. 115).

Nesse aspecto pretendemos mostrar e problematizar fotografias de África presentes em um livro didático ${ }^{3}$ em um tempo em que tanto o mundo da educação como o ensino de Geografia vem sendo chamados a produzir respostas ao racismo e seus impactos na sociedade. Para Santos (2015, p. 322):

as relações raciais grafam o espaço, se constituem no espaço e com o espaço. Revelar estas espacialidades é tarefa da Geografia. Nosso esforço aqui se trata de, ao ler algumas dimensões espaciais das relações raciais, trazer exemplos de discussões que podem ser incorporadas ao ensino escolar da disciplina Geografia.

Transitamos também pelo posicionamento do ensino de Geografia frente à implementação da Lei 10.639 de 2003 que torna obrigatório a inserção de temas referentes à História e Cultura AfroBrasileira na Educação Básica. À Geografia Escolar cabe discutir as "espacialidades das relações raciais" (SANTOS, 2015) assim como construir um olhar que seja capaz de problematizar e combater o eurocentrismo presente na matriz curricular educacional e no ensino de Geografia.

\section{$* * *$}

O encontro de um estudante do Ensino Fundamental com o continente africano, nas aulas de Geografia, se dá, através do livro didático, no último ano desse ciclo. Sim, muito provavelmente esse estudante já viu e ouviu algo sobre África. Partindo de observações anteriores em programas de televisão, filmes ou na mídia imprensa sabemos que África e os africanos estão à margem da "narrativa única da globalização" (MASSEY, 2008), já que viveram seus processos de colonização e descolonização muito recentemente e, que ainda precisariam alcançar melhores indicadores sociais e econômicos para fazer parte do clube dos "desenvolvidos", como se isso fosse possível!

Além disso, há a questão da espacialidade das relações raciais que tem a ver com a ancestralidade geográfica já que a questão racial associa grupos raciais a regiões do planeta. Segundo Santos (2010, p. 145)

[...] "negro" tem a ver com África, confundimos a origem dos fluxos de escravizados trazidos para cá como a única região do mundo onde habitavaám homens e mulheres de pele escura antes do tráfico atlântico, como se as relações entre a África e o resto do mundo fossem inauguradas com as chamadas "Grandes Navegações" - ou, poderíamos dizer para ser mais explícito na ideia que nossa visão de mundo constrói o contato da África com o mundo começa e se dá pelo protagonismo dos Europeus.

E é justamente a partir desse protagonismo que o livro didático inicia a abordagem sobre a Geografia da África: através do imperialismo e do "início da apropriação de territórios pelos europeus". A Geografia do continente é a Geografia do colonialismo europeu.

Um breve texto a respeito do comércio de escravos antecede a questão da apropriação do território partilhado reconhecido pela Conferência de Berlim em 1884.

Duas imagens mapas representando a mudança dos contornos do continente no período de 1880 a 1914 servem para ilustrar o que os autores denominam de "apropriação formal" do território. Espaços retalhados no mapa mostram ao estudante as possessões dos países europeus. No mapa da África de 1914 é possível observar o continente riscado pelas linhas que delimitavam os novos donos dessas terras, as "potências dominadoras" (ADAS; ADAS, 2015, p.218).

A "apropriação formal" do território africano serviu aos avanços da Revolução Industrial e à necessidade de matérias-primas para suprir essa demanda. Além disso:

${ }^{3}$ ADAS, Melhem; ADAS, Sergio. Expedições Geográficas. 2.ed. São Paulo: Moderna, 2015. Este livro didático foi o livro escolhido pelos professores de Geografia da Escola de Educação Básica Simão José Hess, campo de estágio dos acadêmicos do curso de Licenciatura em Geografia da Universidade do Estado de Santa Catarina - UDESC com os quais realizei experimentações com fotografias didáticas de África. 
os progressos técnicos advindos da Revolução Industrial deram aos europeus um poderio bélico esmagador diante dos africanos [...]. As guerras coloniais tornaram-se um incentivo à produção industrial, estimulando a fabricação de ferro, aço, navios, locomotivas, vagões, pólvora, armas, etc. (ADAS; ADAS, 2015 , p. 218).

Nesse contexto também há um pequeno trecho a respeito da resistência dos povos africanos, que não se submeteram a tal "apropriação formal". Uma das duas fotografias presentes nesse Percurso ${ }^{4}$ vem junto ao subtítulo $O$ impacto do neocolonialismo na África (ADAS; ADAS, 2015, p. 219).

Em uma página destinada a essa abordagem, os autores destacam que "o impacto do neocolonialismo dos séculos XIX e XX na África não foi exclusivamente negativo" (ADAS; ADAS, 2015, p.219), porém não apontam quais poderiam ser os aspectos positivos dessa relação de poder que continuou a vigorar nos países africanos e a atender quase que exclusivamente aos interesses dos europeus.

Toda a infraestrutura, por exemplo, no caso dos transportes se limitava a traçar eixos de ligação de zonas de exploração mineral e de produção agrícola aos portos para atender aos interesses dos colonizadores e, não com o intuito de promover uma integração territorial entre os países do continente.

Os sistemas produtivos foram (des)organizados de forma a atender aos interesses e demandas do comércio exterior. Grandes áreas monocultoras de produções destinadas à exportação eram priorizadas em detrimento da produção interna de alimentos.

A fotografia que ocupa o canto direito dessa página mostra dois homens negros no primeiro plano trabalhando no porto de Abidjan, maior cidade e capital econômica da Costa do Marfim. No plano de fundo, é possível observar o que segundo a legenda são carregamentos de grãos de cacau destinados à exportação sendo erguidos por guindastes. A fotografia é de 2011e sua presença na página parece apenas dar veracidade ao texto, ou seja, comprovar o já dito, reforçando as ideias da exclusividade da produção de produtos primários para exportação e da espacialização racial.
FIGURA 1 - Carregamento de sacos de grão de cacau em Abdijan, 2011.

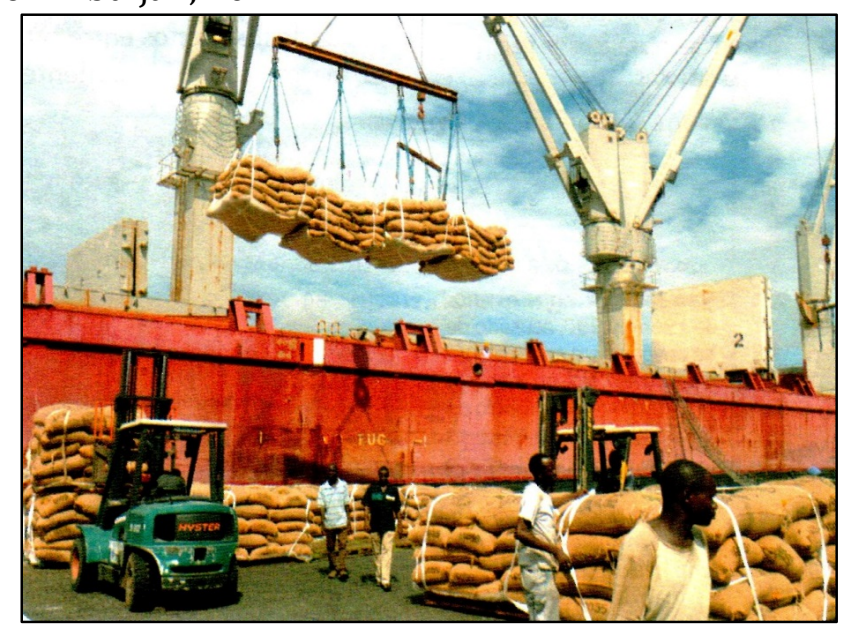

FONTE: ADAS; ADAS (2015)

Outro aspecto levantado pelos autores do livro didático é o do racismo como legado do colonialismo. Em dois parágrafos eles abordam o racismo como herança, como justificativa ou legitimidade da conquista do colonizador que "[...] apoiou-se em um conjunto de ideias ou ideologias preconceituosas e ligadas à intolerância" (ADAS; ADAS, 2015, p. 220). 0 estrangeiro, o civilizado, o conquistador mostra sua superioridade e estabelece comunidades próprias, separadas da população negra.

0 racismo aparece então como questão geográfica, uma vez que criou espaços de exclusão legitimados por um novo mapa desenhado a partir de novas relações de poder.

Nesse caso para Santos (2010, p.145) "[...] a noção de 'europeu' nomeia uma localização de poder na hierarquia etno-racial global"

a 'raça' é então um constructo que, ancorado em leituras do espaço, estrutura também relações de poder com o espaço e no espaço. Leituras de espaço estão, portanto, na base de conformação de nosso padrão de "relações raciais": primeiro, porque leituras de espaço orientam a própria constituição e naturalização da ideia de "raça" e as classificações em grupos raciais; segundo porque são leituras de espaço que estruturam e autorizam as hierarquizações entre os grupos raciais [...].

Percebe-se uma narrativa universal da história, cuja referência "[...] é o eurocentramento espaço-temporal do mundo" (SANTOS, 2010, p. 146). Essa visão de mundo aponta a Europa como superior às "[...] outras regiões geoculturais do planeta" (Idem). 
Seguindo a abordagem sobre racismo encontramos informações sobre a política do apartheid na África do Sul. A política do apartheid é classificado pelos autores como o "exemplo mais cruel e violento de racismo [...]" (ADAS; ADAS, 2015, p.220). Há informações aos estudantes a respeito das leis de segregação racial num país onde uma minoria branca detinha o poder político e econômico sujeitando e reprimindo a maioria da população negra a essa política. Logo após o texto há uma fotografia de Nelson Mandela, símbolo da luta pela igualdade racial.

FIGURA 2 - Nelson Mandela em Mmabatho, África do Sul, 1994.

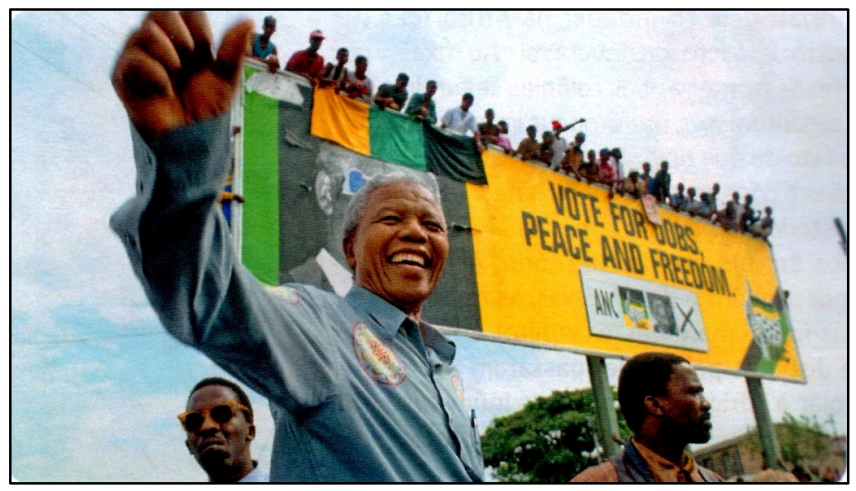

FONTE: ADAS; ADAS (2015)

Após a apresentação das características físicas do continente e da "apropriação formal" do território africano e os impactos do colonialismo europeu, os autores optam, na sequencia, pela abordagem da regionalização e de alguns aspectos populacionais e econômicos do continente.

A regionalização de África divide o mapa em África do Norte e África Subsaariana. Segundo Adas e Adas (2015) essa regionalização toma como base critérios étnico ou cultural. Assim há a África do Norte, com predominância regional da população e língua árabes e a prática do islamismo. A fotografia na parte inferior da página mostra um oásis com plantações em primeiro plano e, ao fundo a Cadeia do Atlas no Marrocos. No texto os autores enfatizam

a cadeia do Atlas favorece o povoamento na África do Norte, especialmente no Magreb. Entre o Atlas e o Mar Mediterrâneo, estendem-se planícies férteis de clima mediterrâneo, densamente povoadas, onde se cultivam vários produtos, como cereais, uvas e oliveiras, e ocorre a exploração mineral do fosfato. Ao sul da Cadeia de Atlas surge o Deserto do Saara cujo principal recurso mineral é o petróleo $(2015, \mathrm{p}$. 228).
FIGURA 3 - Oásis no Marrocos, ao fundo Cadeia do Atlas, 2013.

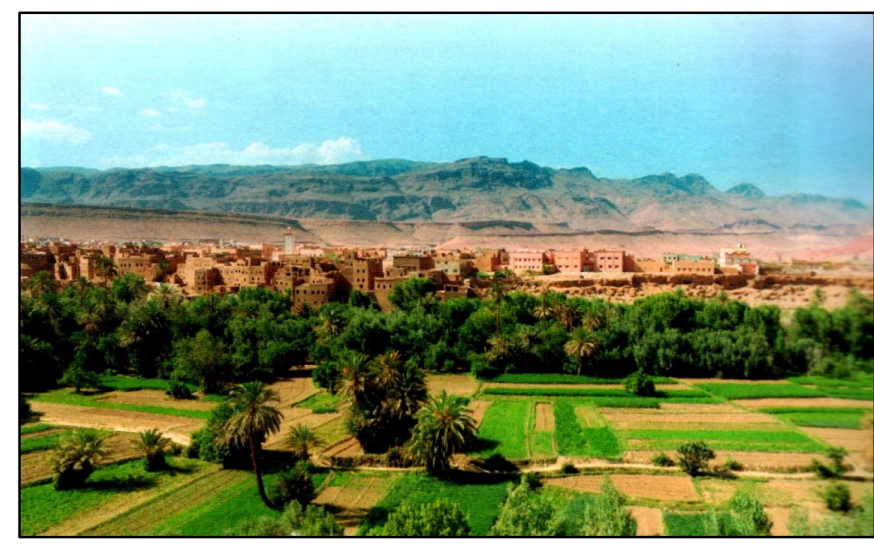

FONTE: ADAS; ADAS (2015)

O texto sobre a África Subsaariana não contempla nenhum aspecto positivo sobre esse território tão amplo e diverso. A começar pela expressão sub é o contraste da África do Norte já que é nesta porção do território africano que a população é branca e se aproxima dos europeus pelo mar Mediterrâneo. Essa ideia faz parte de um pensamento hegemônico dos fins do século XVIII e todo século XIX que excluía a África Subsaariana já que "[...] a história se restringia aos espaços geográficos que tinham como elemento de união o mar Mediterrâneo, promotor da civilização" (HERNANDEZ, 2008, p. 19).

Fica evidente que a ideia de África presente no livro didático é a que reforça a existência de duas Áfricas "[...] com aspectos geográficos diferentes, classificadas em estágios de desenvolvimento diversos, povoadas por etnias distintas, branca e negra e, por fim, uma com e a outra sem história" (HERNADEZ, 2008, p. 21).

A África Subsaariana do livro didático é a região em que a pobreza atinge grande parcela da população, território em que estão os países com os Índices de Desenvolvimento Humano (IDH) mais baixos do mundo. Mais da metade da população economicamente ativa se ocupa da agricultura e, a falta de alimentos gera subnutrição e fome, situação que é agravada pelas secas na região do Sahel e pelas guerras civis, que destroem plantações e, dificultam a entrega de alimentos pela ajuda humanitária.

A agricultura na África Subsaariana apresenta o que os autores chamam de uma "distorção". A distorção é representada pelo fato de que enquanto grandes áreas monocultoras são controladas por empresas europeias, ocupando vastas áreas e as melhores terras, a agricultura de subsistência apresenta baixa produtividade, pois ocupa as áreas menos férteis e os agricultores têm dificuldades de acesso a crédito e assistência técnica. Os autores destacam que essa distorção ou oposição é uma herança do colonialismo que se mantêm na atualidade.

As fotografias na parte inferior da página ilustram o já dito. Marcam e reforçam essa diferença entre agricultura praticada em um país da África do 
Norte e a de um país da África Subsaariana. A primeira fotografia mostra um campo de trigo na Argélia. A cor da vegetação passa a ideia de um local mais árido, mas de agricultura mecanizada, já que as máquinas são o foco da fotografia.

Ao lado aparece uma fotografia da Tanzânia com cores mais vibrantes no plano de fundo, afinal a Tanzânia é um país tropical da África Oriental. Mas em vez das máquinas aparecem dois trabalhadores negros usando enxadas.

FIGURA 4- Campo de trigo na Argélia, 2013.

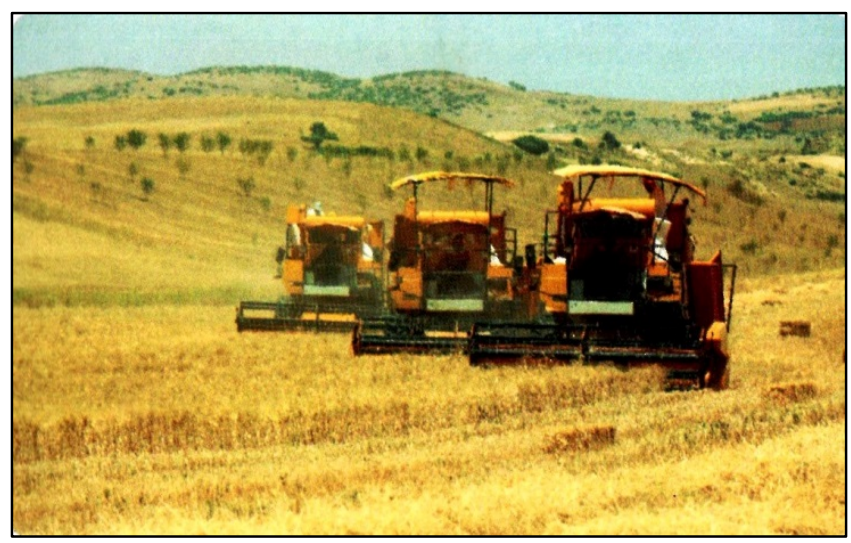

FONTE: ADAS; ADAS (2015)

FIGURA 5 - Agricultura de subsistência na Tanzânia, 2014.

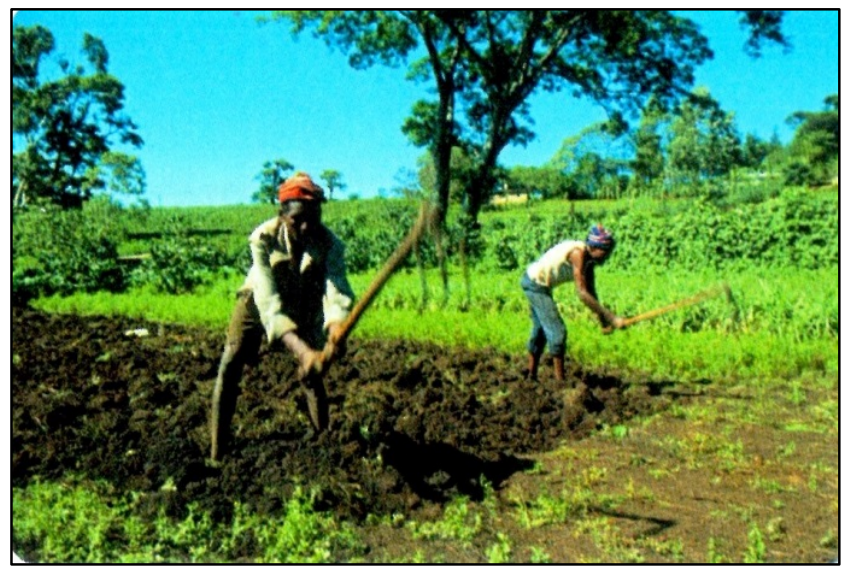

FONTE: ADAS; ADAS (2015)

A partir da mirada dessas fotografias e dos pontos de vista expostos percebemos que as fotografias presentes servem para ilustrar o texto didático, ou seja, estão a serviço do que já foi dito, dão veracidade ao texto, a fotografia que apenas informa (DESIDERIO; TONINI, 2015), que torna imagem o discurso eurocêntrico e põe a mostra mais uma vez a Geografia do colonizador. Miramos o mesmo, o estereótipo, a homogeneização sobre o continente e o reforço da ideia de existência de duas Áfricas e seus contrastes. Nesse sentido, Preve (2013, p. 53) afirma que:

as repetições imagéticas acerca do espaço paralisam o pensamento e asseguram uma comunicação com a informação espacial e não nos impulsionam para uma experiência no e com os espaços. Na escola, as imagens servem aos interesses dos conteúdos que os livros didáticos querem enfatizar. Funcionam como ilustração, confirmando, reafirmando, induzindo, direcionando e entrando em redundância com a explicação. Elas não operam no campo do não dito, mas do já dito.

Imagens-que-dizem-do-mundo (OLIVEIRA JR., 2009), ou de um mundo, um continente inventado. Fotografias que participam da construção de nossa imaginação sobre os lugares e que não escapam à lógica da narrativa do processo de globalização. A lógica ancorada no pensamento de “[...] manutenção da ideia de que o espaço geográfico atual é plenamente globalizado, tendo todos os seus lugares articulados e coerentes entre si posto que a história vivida por nós é uma só e por isso, temos sim lugares adiantados e lugares atrasados no fluxo desta (única) história" (OLIVEIRA JR., 2011, p. 246).

Rio Nilo, savana, deserto, povos nômades, economia de base primário-exportadora, Cairo e África do Sul como únicas possibilidades de se pensar em urbanização em África, o contraste entre a agricultura moderna e a de subsistência marcada por localizações geográficas e relações raciais, a existência e as desigualdades de duas Áfricas, guerras civis, refugiados, AIDS, ebola, desnutrição, fome... ideias que reforçam a imaginação que se constrói a respeito do continente nesse e, em outros livros didáticos utilizados pelas escolas públicas brasileiras e que são avaliados pelo Ministério da Educação.

Com essa leitura não negamos que situações como as apresentadas no livro didático não façam parte do cotidiano dos africanos nos diferentes países que compõem o continente, mas questionamos o fato de serem apenas essas que predominam na construção de saberes sobre África Geografia Escolar quando da utilização de livros didáticos.

Wenceslado Machado de Oliveira Junior e Elaine dos Santos Soares (2013) realizaram uma entrevista com um autor de livros didáticos no Brasil desde a década de 1980: José Eustáquio de Sene, demonstrando o interesse pela pesquisa com imagens fotográficas em livros didáticos. Em alguns trechos da entrevista ${ }^{5}$ fica evidente a importância dos verbos mostrar, ilustrar e comparar quando da escolha de fotografias que compõem os livros didáticos de Geografia: Sene destaca "o mais importante é o conteúdo da foto"; "de fato, a imagem acaba vindo a reboque do texto".

Oliveira Jr e Soares (2013, p.198) destacam a frequência dos grandes planos das fotografias,

\footnotetext{
${ }^{5}$ Entrevista realizada em 16 de abril de 2012. OLIVEIRA JR., Wenceslao Machado de Oliveira; SOARES, Elaine. Entrevista com o Prof. Dr. José Eustáquio de Sene: Fotografias e(m) livros didáticos de Geografia. In: Revista Brasileira de Educação Geográfica. Campinas, v.3, n. 6. P. $192-$
} 225, jul./dez., 2013. 
principalmente de áreas urbanas: "notamos que quase não tem (quando tem alguma coleção) foto de urbanização na África. É um grande vazio, é como se pelo percurso visual, a África não tivesse cidades". Sene justifica essa quase ausência afirmando que há pouca opção de materiais de pesquisa sobre a África, não só material iconográfico, mas também de pesquisa, enfatiza.

Para 0 autor essa dificuldade na disponibilidade de fontes "[...] expressa à própria lógica da globalização. A África é um continente marginalizado". (SENE apud OLIVEIRA JR; SOARES, 2013, p. 199). 0 autor de coleções de livros didáticos usa como exemplo, para justificar a afirmação de continente marginalizado "aquele mapa que mostra o planeta iluminado, os pontos de luz no mundo. As pessoas olham aquela imagem, e poucos se dão conta de que o que veem não existe! Aquela imagem é uma invenção, uma ficção" (SENE apud OLIVEIRA JR; SOARES, 2013, p. 199).

É interessante o destaque que o autor faz sobre a impossibilidade desse mapa existir por conta do movimento de rotação da Terra, ou seja, a Terra sempre tem uma parte iluminada e outra escura. Porém, mesmo assim, quando você observa essa invenção, essa colagem de mosaicos com imagens de satélites a partir da coleta de fotos noturnas, "[...] fica claro que a África é um continente escuro. Isso já é um indício de que possui pouca infraestrutura para sediar os fluxos da globalização. Isso acabou levando com que o continente fique meio esquecido mesmo. Tem menos informações, tem menos bancos de dados em geral, e acaba aparecendo menos" (SENE apud OLIVEIRA JR.; SOARES, 2013, p. 199).

Fica clara aqui a posição do autor em relação ao que Massey (2008, p. 123) chama de "narrativa única da globalização neoliberal", ou seja, "uma interpretação que permeia o discurso popular, político e jornalístico" e, que interfere em nossas imaginações espaciais:

a globalização aqui é tão inevitável quanto a estória da modernidade, e as implicações, mais uma vez são enormes. [...] o Mali e o Chade "ainda" não foram integrados na comunidade global de comunicação instantânea? Não se preocupe; eles o serão em breve. Em breve, neste aspecto, eles serão como "nós". Esta é uma visão a-espacial da globalização. As diferenças potenciais das trajetórias do Mali e do Chade são obstruídas. (As multiplicidades essenciais do espacial são negadas). Supõe-se que tais países estejam seguindo o mesmo ("nosso") caminho do desenvolvimento. (A abertura do futuro que é, em parte, uma consequência das multiplicidades do espacial é refreada. Trata-se de uma narrativa como uma trajetória única [...] (MASSEY, 2008, p.126).
A trajetória única é nesse caso, uma trajetória inventada pelo outro, pelo estrangeiro a partir de novas linhas riscadas no mapa do continente, traçada pelas relações de poder dos colonizadores europeus, restringindo as multiplicidades espaciais e as espacialidades das relações raciais.

0 território, sua gente e suas riquezas tornam-se coisas, lugares que ainda precisam "avançar" muito para chegar a um padrão estabelecido, para alcançar uma posição no mundo globalizado frente à negação de suas próprias histórias e trajetórias no e com o espaço.

À escola e ao ensino de Geografia cabe esse lugar de oficina de invenção de uma única ideia de África quando simplesmente tornam invisíveis às fotografias do livro didático ou as colocam apenas como prova ou ilustração do assunto que está sendo apresentando no texto escrito, sem problematiza-las. Nesse aspecto, concordamos com Oliveira Jr. e Soares (2012, p. 115) quando dizem que "esta maneira de entrar em contato com as fotografias restringem-nas, fazendo-as ser pouco mobilizadoras do pensamento das crianças e adolescentes em situações escolares", ou seja, precisamos desloca-las desse lugar que ocupam para compormos outras possibilidades de construção de saberes sobre Áfricas.

\section{3 ÁFRICA TODO DIA: EXPERIMENTAÇõES COM FOTOGRAFIAS}

Na tentativa de mobilizar o pensamento a respeito do bloco visual do continente africano que tínhamos observado e discutido a partir da mirada no livro didático da escola campo de estágio e em outros também propus encontros com outras fotografias e solicitei aos professores em formação inicial que se deixassem guiar pela "aventura" que essas poderiam lhe causar.

Roland Barthes em sua obra A câmara clara (2012) decide em certo momento de sua análise tomar como guia a atração que sentia por certas fotos. Usou então a palavra aventura para designar essa atração que sentia por certas fotografias em detrimento de outras. Dizia Barthes que (2012, p. 27) "o princípio de aventura permite-me fazer existir a Fotografia. De um modo inverso, não há foto sem aventura".

Do ponto de vista da Geografia Escolar caberiam duas questões: como mobilizar o pensamento diante das fotografias didáticas sobre África? Que outras fotografias podem permitir uma construção de saberes sobre África(s)?

Ao perceber que a grande maioria dos estudantes/professores em formação inicial concentrava grande tempo de suas atenções em seus telefones celulares, propus que começassem a seguir um perfil no Instagran chamado @everydayafrica ${ }^{6}$. E

6Projeto que surgiu na África há cerca de quatro anos, idealizado por fotógrafos estadunidenses baseados no Quênia com o objetivo de desconstruir os clichês de fome, pobreza e destruição atribuídos ao imaginário do continente. 0 perfil ganhou milhares de seguidores e, inspirou outros profissionais a criar iniciativas similares como, por 
eram as fotografias compartilhadas neste perfil que começaram a mobilizar as nossas conversas e pensamentos.

Semanalmente, pelo menos duas fotografias iniciavam nossos encontros e conversas na tentativa de estabelecer um espaço para exercitar o pensamento, um momento de parar e mirar fotografias que atraíam cada um dos estudantes, professores em formação inicial, que cursavam a disciplina.

Em encontros anteriores já havíamos discutido a respeito de como aprendemos sobre África em situações escolares/didáticas e na mídia em geral enquanto analisamos as fotografias dos livros didáticos e discutimos as relações de poder imbricadas na questão das relações raciais e como essas se reproduzem na leitura do espaço geográfico africano. Como apresentamos na seção anterior do trabalho, a ideia de África presente nos livros didáticos reproduz e reforça diversas invenções oriundas da colonialidade do ser, do saber e do poder. As fotografias presentes nos livros ilustram o já dito pelo texto e não são mobilizadoras de pensamento para essas invenções criadas a respeito de África e sua gente.

São imagens que circulam em ambientes de construção de saberes (escola e mídia em geral) que não são capazes de mostrar ao mundo possibilidades de conhecer e construir África(s), de enxergar sua gente e as relações cotidianas que estabelecem no e com os diferentes espaços, ressaltando suas forças econômicas, suas formas de organizações sociais e políticas, suas relações de espacialidade, sua posição no mundo globalizado, ou seja, a produção de suas próprias histórias.

Assim, aparece o Everyday África. $\mathrm{Na}$ tentativa de quebrar esse fluxo de falta de informação e formar um retrato mais completo do continente, os americanos Peter Di Campo e Austin Merrill tiveram a ideia de agregar em um site fotografias tiradas a partir de telefone celular em qualquer lugar em toda a África. 0 projeto que conta com muitos fotógrafos contribuintes "é uma resposta à representação da mídia comum sobre o continente africano como um lugar consumido pela guerra, pobreza e doença" (STRECKER, s/d).

$\mathrm{Na}$ composição de fotografias do portfólio, encontramos trabalhos de jornalistas africanos ou que viveram e trabalharam no continente por anos ou por um curto período, além de cidadãos interessados que usam a hashtageverydayafrica ou artistas engajados. "O resultado dessa composição é prova de que o retrato dos extremos não prevalece com a mesma força que o familiar, o cotidiano" (STRECKER, s/d).

Em cada encontro miramos fotografias escolhidas por cada um dos estudantes, professores em formação inicial, e discutíamos a respeito do quanto às mesmas mobilizam nossa imaginação de África, deslocavam nossos pensamentos do já dito, do clichê e ampliavam as perspectivas para criarmos outras ideias do continente, mesmo que de forma ainda muito incipiente.

Neste trabalho, decido mostrar três fotografias que circularam por nossos encontros a partir do uso do aplicativo Instagranatravés do perfil @everydayafrica.

FIGURA 5 - Mulheres fazendo selfiesem Lagos, Nigéria.

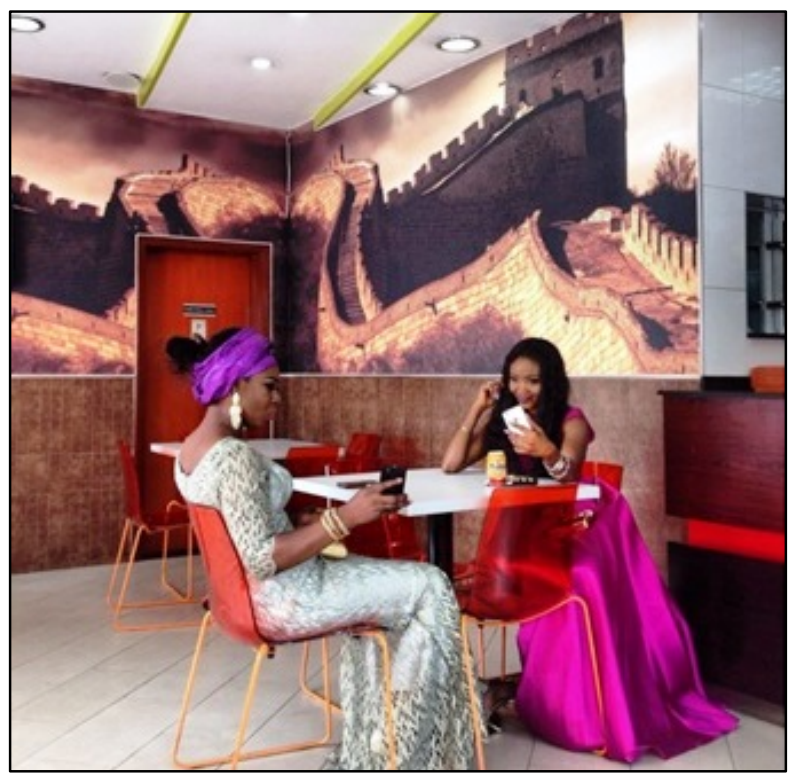

FONTE: ESIEBO, (2016).

Em um local que parece ser uma lanchonete, duas mulheres com vestidos longos e acessórios fazem selfies com seus celulares, mostrando uma cena bem comum no cotidiano nas grandes cidades. 0 que atrai nessa fotografia?

a foto acima, tirada por Andrew Esiebo, fotógrafo nigeriano, retrata duas mulheres em uma lanchonete na capital Lagos (Nigéria), localizada em um shopping. Escolhi apresentar essa imagem, raramente vista por nós ocidentais, pois revela um lado vaidoso da mulher africana, seja através de vestidos luxuosos, acessórios chamativos ou até a própria "selfie", ícone de uma geração imodesta. Intitulada "Selfish", o editorial de Andrew Esiebo amplia a visão de vaidade e egocentrismo que as mulheres africanas detêm, contrapondo minha prévia visão de que são mulheres carentes de cuidados, vítimas de alguma condição socioambiental negativa ou que beiram a miséria (sic) (Julia, estudante, professora em formação inicial, 2016). 
FIGURA 6 - Homem vestido de Papai Noel no Senegal, 2015.

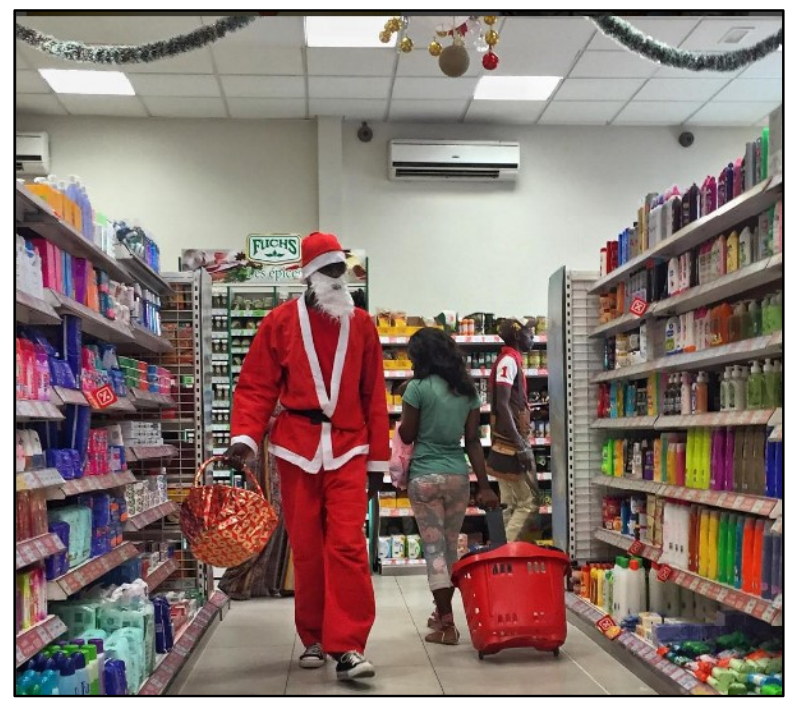

FONTE: SHRYOCK, (2016)

a segunda foto eu gostei mais ainda, mostra um homem vestido de Papai Noel fazendo compras no supermercado. Segundo a legenda este registro é do Senegal, e destaca que, apesar deste país ser de absoluta maioria muçulmana, alguns locais se enfeitam para o natal, como por exemplo, o estabelecimento da imagem. 0 cidadão que interpreta 0 Papai NoeI deixa o posto de trabalho por um momento e realiza suas compras. Uma imagem que retrada um cotidiano presente em qualquer Iugar, fora a roupa de Papai NoeI, que de certa forma é também muito normaI em países cristãos, como o Brasil. A espontaneidade e simplicidade me tocou, algo singelo e que me passou realidade, vida real, de pessoas reais no seu cotidiano real" (sic) (João, 2016).

Além da discussão das próprias fotografias e do que podíamos com elas em termos de mobilização de pensamento nos perguntávamos "que potências surgem dessas miradas"?

A busca é a de arrancar a linguagem fotográfica do silenciamento a que está submetida nos ambientes e materiais didáticos habituais ao ser tomada como documento de uma realidade que préexistia ao ato de fotografar. Intentamos retirar as fotografias deste sentido fixo de documento do real, deste desejo da representação fidedigna, buscando movimentar as fotografias nos pensamentos a partir de diversas formas de fabular a partir do entre que se cria no encontro de estudantes e fotografias presentes em livros didáticos de Geografia, retomando assim essas fotos para o mergulho nas subjetividades engendradas nas escolas (OLIVEIRA JR.; SOARES, 2012, p. 116).

A fotografia a seguir carrega outras possibilidades de sentidos.

FIGURA 7 - Crianças em Lagos-Nigéria, 2015.

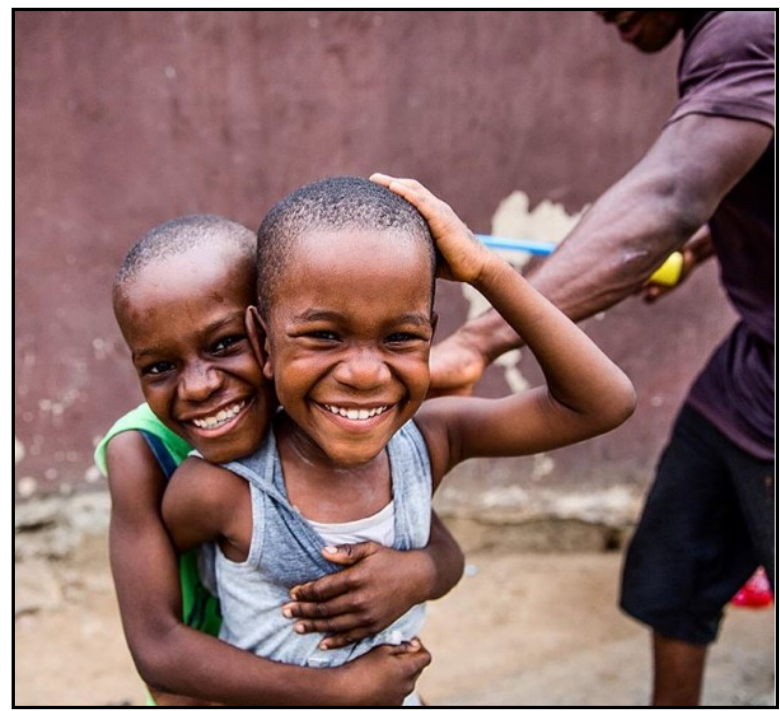

FONTE: SAATER, (2015).

Essa "foto mostra duas crianças se abraçando e rindo, MUITO diferente das imagens de crianças subnutridas, chorando e doentes, que estamos acostumados a ver nas mídias formadoras de opinião" (sic) (Larissa, 2016).

A mirada para as fotografias do EverydayÀfrica não tinha como intuito a simples substituição das fotografias do livro didático mas mostrar como essas a insistência nas invenções criadas, na reprodução de clichês, nos reforços de atraso, de pobreza, fome, miséria e toda narrativa pronta que encontramos nesses livros, nesses programas de televisão, no discurso do senso comum.

Quando as fotografias didáticas se encontram com as fotografias do perfil algo acontece

[...] pensamentos que não busquem dar sentidos únicos e prováveis às fotos, mas que manipulem-nas de modo a abri-las para outras paragens, para outros significados, outros sentidos (ou mesmo sem sentidos) que não sejam absolutos, nem verdades, muito menos estáticos, mas que sejam móveis, mutáveis, dúbios, transformadores, que disparem sensações e pensamentos que abram vão no entre-imagens que pode vir-a-ser qualquer fotografia.(OLIVEIRA JR, SOARES, 2012, p.116

Procurar, nesses espaços de formação, por exercícios que valorizem a experiência em detrimento da informação, a mobilização do pensamento sobre os lugares do mundo a partir das 
fotografias e sua potência educativa em situações escolares ou não.

Que situações encontraríamos então nos espaços de formação incial de professores e nas escolas se passássemos a lidar com as fotografias didáticas para além do sentido ilustrativo e/ou documental que as atravessa? Que "alternativas ao eurocentrismo", Santos (2010, p. 151), poderíamos criar em situações de uso dessa linguagem na Geografia Escolar? Que forças, que possibilidades e sentidos poderíamos criar com essas fotografias que circulam nos materiais didáticos e no caso deste trabalho, nas fotografias presentes em uma rede social?

Neste contexto, concluímos que as experimentações com as fotografias que mostram o cotidiano do continente africano são potentes para deslocarmos a fotografia desse lugar de aprisionamento, de prova documental para encontrar nelas possibilidades de criações expressivas que não sejam universais ou influenciadas apenas pelas narrativas eurocentradas.

\section{REFERÊNCIAS}

ACHEBE, Chinua. A educação de uma criança sob o Protetorado Britânico: ensaios. Trad. de Isa Mara Lando. São Paulo: Companhia das Letras, 2012.

ADAS, M.; ADAS, S. Expedições Geográficas.

Componente Curricular Geografia. 9o ano. 2.ed. São

Paulo: Moderna, 2015.

BARTHES, Roland. A câmara clara. Nota sobre a Fotografia. Trad. de Manuela Torres. Lisboa: Edições 70, 2012.

BRASIL, Lei no 10.639 de 9 de janeiro de 2003. Ministério da Educação. Diretrizes Curriculares Nacionais para a Educação das Relações Étnico Raciais e para o Ensino de História e Cultura AfroBrasileira e Africana. MEC/SECAD: Brasília. 2005.

DESIDERIO, Raphaela de Toledo; TONINI, Ivaine Maria. África todo dia: uma experimentação em fotografias na educação geográfica. Memorias do XV Encuentro de Geógrafos de América Latina: "Por uma América Latina unida y sustentable”. La Habana, Cuba. 06 a 10 de abril de 2015. (cd-rom).

HERNANDEZ, Leila Leite. A África na sala de aula: visita à história contemporânea. 2.ed.rev. São Paulo: Selo Negro, 2008.

LARROSA, Jorge. Pedagogia Profana: Danças, Piruetas e Mascarados. Trad. de Alfredo Veiga-Neto. 4. ed. Belo Horizonte: Autêntica, 2004.

MASSEY, Doreen. Pelo espaço: uma nova política da espacialidade. Trad. de Hilda Pareto Maciel e Rogério Haesbaert. Rio de Janeiro: Bertrand Brasil, 2008.
Elaine dos Santos. Entrevista com o Prof. Dr. José Eustáquio de Sene: Fotografias e(m) livros didáticos de Geografia. In: Revista Brasileira de Educação Geográfica. Campinas, v.3, n.6, p 192 - 225, jul./dez. 2013.

.; SOARES, Elaine dos Santos. Fotografias didáticas e Geografia Escolar: entre evidências e fabulações. In: Revista Percursos. Florianópolis, v.13, n.2, p 114-133, jul./dez. 2012.

Grafar o espaço, educar os olhos. Rumo a Geografias menores. In: Revista Pro-posições: Dossiê A educação pelas imagens e suas Geografia s. Revista Quadrimestral da Faculdade de Educação UNICAMP, v.20, n.3 (60), set./dez. 2009.

PREVE, Ana Maria Hoepers. Geografia s, Imagens e Educação: Experiências. In: Revista Entre-lugar. Revista do Programa de Pós-graduação em Geografia da Universidade Federal da Grande Dourados, MS. v.4, n.7, p. 49-66. 1. Semestre de 2013. Disponível em:

<http://ojs.ws.ufgd.edu.br/index.php?journal=entre

lugar\&page $=$ article \&op=view\&path $\% 5 B \% 5 \mathrm{D}=2673$ \&path\%5B\%5D=1520.> Acesso em: 10 set. 2013.

STRECKER, Iris. Everyday África - uma África mais completa pelas lentes dos celulares. Disponível em: $<$ http://www.afreaka.com.br/notas/everydayafrica-uma-africa-mais-completa-pelas-lentes-doscelulares/.> Acesso em: 10 maio 2016.

SANTOS, Renato Emerson dos. Ensino de Geografia e Currículo: questões a partir da Lei 10.639. In: Revista Terra Livre. São Paulo: AGB, ano 26. V.1, n.34. p.141160, jan-jun/2010.

SONTAG, Susan. Sobre fotografia. Trad. de Rubens Figueiredo. São Paulo: Companhia das Letras, 2004.

TONINI, Ivaine Maria. Livro didático: Textualidades em rede? In: TONINI, I. M.; GOULART, L.B.; MARTINS, R. E. W. (org.). O ensino de Geografia e suas composições curriculares. Porto Alegre: UFRGS, 2011.

VALLADARES, Marisa. Abóboras ao vento... A propaganda no ensino de Geografia. Disponível em: <http://www.geoimagens.net/\#!__es/textos.> Acesso em: 10 fev. 2015. 